in vivo $35: 53-60(2021)$

doi:10.21873/invivo.12231

Review

\title{
The Role of Nutritional Support in Malnourished Patients With Lung Cancer
}

\author{
AGATA KASPRZYK ${ }^{1}$, KRZYSZTOF BILMIN ${ }^{1}$, TOMIRA CHMIELEWSKA-IGNATOWICZ ${ }^{1}$, \\ JAKUB PAWLIKOWSKI ${ }^{2,3}$, URSZULA RELIGIONI ${ }^{4}$ and PIOTR MERKS ${ }^{1,5}$ \\ ${ }^{1}$ Faculty of Medicine, Collegium Medicum, Cardinal Stefan Wyszyński University, Warsaw, Poland; \\ ${ }^{2}$ Chair and Department of Humanities and Medical Sociology, Medical University of Lublin, Lublin, Poland; \\ ${ }^{3}$ Biobanking and Biomolecular Resources Research Infrastructure (BBMRI.pl), Warsaw, Poland; \\ ${ }^{5}$ Warsaw School of Economics, Warsaw, Poland; \\ ${ }^{4}$ Faculty of Pharmacy, Collegium Medicum in Bydgoszcz, Bydgoszcz, Poland
}

\begin{abstract}
This review aimed to aggregate and describe the available data about clinical nutrition in lung cancer and the role of the dietitian in multidisciplinary patient care. Scientific literature was searched in order to summarize key aspects related to clinical nutrition in lung cancer. This information can be used to arrange a proper nutritional therapy that can enhance patient treatment responses, prevent side-effects, shorten recovery time, improve prognosis and increase quality of life. An anti-inflammatory diet rich in antioxidants, immunomodulatory compounds, dietary fibre and an appropriate intake of protein can reduce the risk of initiation and progression of lung cancer, support the regeneration of tissues (also after surgery) and improve the nutritional status during the disease and after remission. A correct intake of nutrients is significant prior to disease occurrence and at every stage of treatment and recovery.
\end{abstract}

Lung cancer is the most common type of cancer and a leading cause of cancer death (1). The most common causes of this cancer include both active and passive smoking, as well as poisoning with heavy metals, asbestos and other carcinogenic substances (poor air quality) (2). Lung treatment is based on tumour resection, chemotherapy and radiotherapy. The consequences of a systemic treatment may include problems with swallowing, coughing, persistent dyspnoea and recurrent

This article is freely accessible online.

Correspondence to: Piotr Merks, Faculty of Medicine, Collegium Medicum, Cardinal Stefan Wyszyński University, 1/3 Wóycickiego St., 01-938 Warsaw, Poland. E-mail: piotrmerks@googlemail.com

Key Words: Clinical nutrition, oncology nutrition, lung cancer, malnutrition, cancer recovery, review. pneumonia. All these symptoms have a negative impact on the type and amount of food consumed, as well as patient quality of life. Unfortunately, in many cases, malnutrition and cachexia are diagnosed before initiating systemic treatment. Studies show that malnourished patients after surgery (non-small cell lung cancer, NSCLC) have a shorter survival time and greater postoperative complications. Malnutrition weakens intercostal muscles and the immune system. It also contributes to infectious complications, increasing the risk of death. This is why appropriate nutritional therapy is significant before and during systemic treatment, as well as during patient recovery (3).

The aim of this review was to describe the available data about clinical nutrition in patients with lung cancer. A scientific literature review was carried out to summarize key aspects related to clinical nutrition in lung cancer. The following search strategy was applied: Articles were extracted from PubMed using the terms "clinical nutrition", "nutrition", and "malnoutrition" in combination with "lung cancer".

We describe the effect of pharmacological treatment on malnutrition in patients, the prevalence of malnutrition in patients with lung cancer, and the role of individual food components in the process of patient therapy.

\section{Epidemiology}

The annual death rate due to lung cancer worldwide is very high at about 1.8 million (1). It is estimated that by 2035, this number will have increased to 3 million (4). Additionally, an increased risk of lung cancer among women is observed every year. The 5-year survival rate is currently $15 \%$ (4), and largely depends on the type and clinical stage of the cancer. The highest chance of survival $(25 \%)$ is observed in patients with early diagnosed cancer, and 5-year survival rates are 1-5\% in the case of advanced disease (5). 


\section{Etiology and the Impact of Diet on Cancer Risk}

Lung cancer arises in epithelial cells that line the airways and is caused, among others, by mutations associated with carcinogenic factors. The most significant factor that increases the risk of this disease is active smoking. Furthermore, secondhand smoke and smoking cessation also have an essentially negative influence on the likelihood of the disease (6). Secondhand smoke, exposure to asbestos, heavy metals (cadmium, lead, nickel, arsenic) and other carcinogenic chemical substances, as well as air pollution, can also be risk factors (2). Too low $\left(<18.5 \mathrm{~kg} / \mathrm{m}^{2}\right)$ and too high $\left(>30 \mathrm{~kg} / \mathrm{m}^{2}\right)$ a body mass index (BMI), are also considered lung cancer risk factors (7). Nutrition is probably only significant in the context of the influence on the pace and tendency of tumourigenesis, which is reflected in the results of studies on the impact of particular nutrients (antioxidants, polyphenols, dietary fibre) and the entire nutritional model. Vegetables, fruit, white meat and soya products are mentioned as being particularly useful in reducing the risk of tumourigenesis $(8,9)$. In the pre-diagnosis period, nutrition and the resulting nutritional status (especially rapid weight loss), as well as patient general fitness have a significant impact on the prognosis in those with advanced cancer (10).

The pathophysiological mechanism of lung cancer is similar to chronic obstructive lung disease, and includes the participation of chronic inflammation in the airways, oxidative stress, protease-antiprotease imbalance, and disturbed repair mechanisms. The significant role of inflammatory factors in tumorigenesis is indicated, among others, by the essential role of C-reactive protein as a prognostic marker of lung cancer and its progression (11). Moreover, a lower pre-albumin level in this group, which is also a marker of the nutritional status, combined with oxidative stress and the specific microenvironment within the lung tissue changed by carcinogenic factors, are the probable causes of disorders in the anticancer abilities of the immune system and the progression of cancer (12). The growth of cancer, facilitated by so-called immune tolerance, reduces the efficiency of cytotoxicity or increases the susceptibility of lymphocytes to apoptosis. Due to a heterogenic antigen structure and differences in phenotype of cells of various types of lung cancer, the responses of the immune system are disturbed and oriented to immunosuppressive reactions, which is caused by hypoxia in tissues changed by cancer and an excess of the cytokines, chemokines and metabolites it produces (e.g. interleukin 10 and transforming growth factor- $\beta$ increase the growth of forkhead box P3 regulatory T-cells that take part in the development of immune tolerance) (13). Given the above, a reduction in the factors favouring chronic inflammation (stress, unhealed infections, obesity) and the appropriate supply of nutrients (including antioxidants and immune modulators) may have a potential impact on lowering the risk of disease initiation and progression.

\section{Symptoms and the Quality of Life of Surgical Patients}

Lung cancer is divided into non-small cell lung cancer (NSCLC) (85\%), including adenocarcinoma (the most frequent subtype in non-smokers), squamous cell carcinoma, small-cell lung cancer, giant-cell carcinoma, and others not specified. Lung cancer metastases are most common in regional lymph nodes, and then in the liver, brain, the other lung, bones, adrenal glands, subcutaneous tissue and bone marrow. Infiltration of mediastinal anatomic structures, diaphragm, pleura and chest walls (10). The most common symptoms of lung cancer include a cough or one that changes in character, dyspnoea, haemoptysis, hoarseness, chest pain, recurrent or chronic pneumonia, problems with swallowing, shoulder pain, superior vena cava syndrome and Horner syndrome. In addition, there are non-specific general symptoms, such as general weakness, weight loss, elevated body temperature, joint pain, exteroceptive sensory abnormalities and symptoms of thrombophlebitis (14). The most common symptoms reported by patients are: weakness (98\%), loss of appetite (98\%), breathing problems $(94 \%)$, cough $(93 \%)$, pain $(90 \%)$ and haemoptysis $(70 \%)(15)$, the intensity of which correlates directly with patient quality of life (16). It was also found that the ability to function in daily life, established on the basis of questionnaires assessing quality of life, depends on the type of cancer, comorbidities and chemotherapy that directly determine the intensity of symptoms (16).

Treatment of lung cancer depends strictly on its type. In patients with NSCLC (excluding some stage III cancer), first-line therapy is lung parenchymal resection through lobectomy, more seldom pneumonectomy, with obligatory lymphadenectomy. Radiotherapy is applied when there are some medical contraindications or the patient refuses consent to surgery.

Survival time varies depending on the type of cancer and the time of diagnosis (stage of disease), and prognosis is worse for small-cell lung cancer and metastatic cancer (17). The symptoms that influence the quality of life of surgical patients include insomnia, and more seldom, coughing and haemoptysis (18). The negative prognostic survival factors following treatment are loss of appetite, diarrhoeas, fatigue and depression (19). Even at 2 years after surgery, some patients experience pain, fatigue, dyspnoea and coughing, which can be minimised to some extent by ceasing smoking, better control of health, and improved physical functions that are taken into account for the overall evaluation of the quality of life (20). This evaluation also has a prognostic value during remission. On the basis of the European Organization for Research and Treatment of Cancer Quality of Life Questionnaire - Core 30 and Quality of Life Questionnaire Lung Cancer Module 13 questionnaires dedicated to patients with lung cancer, significant dependence between physical 
functioning, insomnia, general sense of vigour, sense of anxiety and patient prognosis can be observed. This dependency can be influenced by proinflammatory factors (proinflammatory tumor necrosis factor $\alpha$ ) and vascular endothelial growth factor (cytokine) that correlate with the aforementioned symptoms (21) and potentially lower motivation to implement medical recommendations, including those related to changes in lifestyle, which is observed in patients with a low quality of life (22). Non-pharmacological factors that may potentially improve the quality of life of patients with lung cancer include physical activity, devoting time to leisure, reduction of stress and appropriate diet (23).

\section{Pharmacological Treatment and its Influence on Malnutrition}

In patients with NSCLC, the most commonly used chemotherapeutics are cisplatin and vinorelbine, usually administered in 3-4 cycles. In other cases, the basic treatment methods are radiotherapy alone or in combination with chemotherapy, or systemic treatment with the use of cisplatin, etoposide, vinorelbine, docetaxel, paclitaxel, pemetrexed, gemcitabine, carboplatin or other agents in various combinations. In patients with oncogenic epidermal growth factor receptor mutations or anaplastic lymphoma kinase gene rearrangement, the first-line therapy is tyrosine kinase inhibitors $(24,25)$. A permanent method in NSCLC treatment is also immunotherapy; in this indication, antibodies to programmed death receptor 1 , such as pembrolizumab, as well as those against programmed death-ligand 1, nivolumab and atezolizumab, have already been registered. Chemotherapy is associated with numerous adverse effects, where apart from gastrointestinal and hematopoietic system disorders, interactions with consumed nutrients are also of great significance. For example, administration of cisplatin is associated with reduced absorption and increased excretion of magnesium, and administration of pemetrexed is associated with folic acid deficiency (26). Supplementation of low doses of folic acid in pemetrexed therapy is an essential element of premedication. As the above data shows, the disease itself and surgical treatment are factors predisposing to undernourishment, and the applied pharmacological treatment may affect the nutritional status of patients with lung cancer.

\section{Malnutrition in Patients With Lung Cancer}

Malnutrition in lung cancer before treatment is found in 26$40 \%$ of cases, depending on the tool used for assessment - the nutritional status assessment questionnaire: Subjective Global Assessment (SGA) (27), Patient Generated-SGA (28) or Mini Nutritional Assessment (29). The status of malnutrition, resulting from an insufficient intake of nutrients or abnormal absorption, has a negative impact on the survival prognosis, quality of life and side-effects of treatment (27). The prognostic value, correlating with the chance of survival, is also reflected by the serum albumin level and the Karnofsky Performance Status Scale (29). BMI, used to evaluate the nutritional status of healthy people, is not important in oncological patients (30). In a study by Sanchez et al. (27), in a group of patients with NSCLC undergoing chemotherapy, the average BMI was $24.8 \mathrm{~kg} / \mathrm{m}^{2}$, which is a normal body weight. Nevertheless, after evaluating the nutritional status with the SGA questionnaire, malnutrition was indicated in over $60 \%$ of the patients, and the average body weight loss was $8.4 \%$. BMI measurement, without an evaluation of malnutrition risk factors, is not accurate due to increased fluid retention in patients undergoing intensive treatment, and lack of evaluation of the possibility of compensation of disturbed metabolic processes. Low nutritional status in patients with lung cancer correlates with the overall assessment of their quality of life, and particularly with loss of appetite, fatigue, dyspnoea and diarrhoeas. The occurrence of the aforementioned symptoms may be both the effect and cause of malnutrition, which indicates that patients showing these symptoms should be placed under special nutritional supervision $(27,31)$.

An indicator with a potentially broader use is bioelectrical impedance analysis for estimating fat and muscle mass, as well as phase angle, which shows the integrity and function of cellular membranes. The loss of this function is observed e.g. in liver cirrhosis, conditions requiring haemodialysis, cancers and human immunodeficiency virus. Despite no standards and norms for this parameter, many studies show the dependency between a higher value of phase angle and better patient health, while a lower value may indicate inflammation or malnutrition that partially determines the survival time and patient prognosis (32).

In a study by Sanchez et al., the average phase angle in cancer patients was $5.8 \%$ (27), while in healthy people it is usually $7.32 \%$ (33). In a study by Gupta et al. conducted among a group of patients with stage III and IV NSCLC, the average phase angle was $4.4 \%$, with the average survival time of the patients with a phase angle $\leq 5.3^{\circ}$ was 7.6 months, compared to 12.4 months for the remainder of the group (34). In addition, it was observed that the phase angle in patients with lung cancer correlated with the result of the Karnofsky Performance Status Scale and severity of the disease, including the size of the tumour (35).

On diagnosis of lung cancer, the proportion of patients with low body weight is usually low (3-7.5\%), while in the case of patients with excessive body weight, it is about $37-49 \%$ (3638). Body weight loss prior to treatment is observed in about $58 \%$ of patients with NSCLC, $59 \%$ of patients with small cell lung cancer, and $76 \%$ of patients with pleural mesothelioma (39), and usually increases over the course of chemotherapy. 
This is caused, among others, by intense metabolic processes and eating fewer meals (loss of appetite, gastrointestinal disorders) resulting from aggressive anticancer treatment. It is possible for some patients to maintain their body weight, yet this does not mean a lack of changes in body composition or the need for nutritional supervision. Nattenmüller et al. studied the nutritional status and body composition of a group of 200 newly diagnosed patients with lung cancer (37). Using computed tomography, the body composition of the patients was analysed twice, prior to chemotherapy and following the first-line treatment, and the results compared. Analysis showed a statistically significant increase in fat tissue, both visceral adipose and subcutaneous tissue, in the studied group and a decrease in muscle mass. The body composition parameters that had a negative impact on prognosis included a lower percentage share of muscle tissue and a higher percentage share of visceral adipose tissue measured prior to treatment. The significant parameters following chemotherapy included body weight loss, lower BMI, muscle mass loss and increased content of total fat tissue. It is worth noting that there was only a slight decrease in BMI and no significant differences in body mass were observed, thus indicating the real character of the change in body composition in oncological patients. This not only shows that body weight loss is an unfavourable prognostic factor, but also that muscle tissue loss is a source of protein in the period of increased demand for nutrients (40). Sarcopenia among patients with lung cancer was also noted in the studies carried out by Baracos et al. (38) and Prado et al. (41), which suggests that all patients should be under the care of a nutritional team and immediate nutritional intervention should be considered from the very beginning of treatment to maintain/increase muscle mass, and preventing an increase in fat tissue. Bioelectrical impedance analysis conducted in hospitals would enable early diagnosis of unfavourable changes in body composition and better adjustment of dietary ingredients to patient needs.

\section{Nutrients Supporting Anticancer Therapies and Recovery}

Surgical treatment of lung cancer is applied in most patients with early-stage NSCLC (10). One of the factors determining surgery is a good general condition of the patient, which also includes their nutritional status. Studies carried out among patients awaiting surgery for lung cancer have shown that malnourished patients had a shorter survival time and a higher risk for postoperative complications than those with normal nutritional status or BMI $>18.5 \mathrm{~kg} / \mathrm{m}^{2}(42-44)$. This is probably due to weakened respiratory muscles and immune system response caused by a deficiency in essential nutrients, which would result in e.g. an increased infection risk. In a stressful situation, like surgery, and as a result of the destructive effect of cancer, it seems critical to support the immune system by increasing the supply of immuno- modulatory compounds and antioxidants that are believed to reduce reactive oxygen species (ROS).

\section{Vitamins and Minerals}

Components with a protective effect on immune system cells, which are particularly susceptible to ROS, include $\beta$-carotene, vitamins $C$ and E, selenium, and zinc (45). Selenium deficiency weakens the immune system response to bacterial and viral infections, lowers the activity of T-lymphocytes, macrophages and natural killer cells, as well as disturbing the synthesis of prostaglandins and immunoglobulins (46). Zinc deficiency disturbs chemotaxis, natural killer cells and the phagocytic ability of macrophages, as well as lowering the total number of B-lymphocytes (47). Vitamin D, whose receptors are found e.g. on macrophages, monocytes, dendritic cells and active T- and B-lymphocytes, has the capacity to modulate the suppression of immune responses (48). Vitamin A plays a crucial role in the process of maturation and differentiation of the immune system cells. One of the functions of vitamin $\mathrm{C}$ is its participation in the process of immune responses to tissue damage, which affects the process of mitosis and migration of monocytes to the area of damage, and also the transition of macrophages during the inflammatory phase (49). The influence of vitamins $\mathrm{C}$ and $\mathrm{E}$ and $\beta$-carotene supplementation was evaluated in a study by Pathak et al. carried out among a group of patients with stage IIIb and IV NSCLC undergoing chemotherapy with carboplatin and paclitaxel. The intervention resulted in higher but statistically insignificant results related to the average survival time (9 vs. 11 months), total survival time in a year (32.9\% vs. $39.1 \%)$ and 2 years $(11.1 \%$ vs. $15.6 \%)$, and total percentage of response to treatment (33\% vs. 37\%) in the group of patients taking supplements, compared to the control group (50). Despite no improvement in the treatment results, this study demonstrated that there is no negative influence of antioxidant supplementation on the anticancer effect of chemotherapeutics. Some studies showed additional benefits of the inclusion of antioxidants before and during radiotherapy and chemotherapy (51). In an article by Prasad, the suggestion for a protocol related to antioxidant supplementation before and during cancer treatment was presented. It includes an increased supply of vitamins A, C, E and D, B-group vitamins, $\beta$-carotene and minerals, excluding iron, copper and manganese that generate ROS in an environment rich in antioxidants. The protocol, dedicated to the period following anticancer treatment that is supposed to prevent disease recurrence, includes an additional portion of vitamins $C$ and $\mathrm{E}$ and $\beta$-carotene. The author also points out the benefits of a low-fat high-fibre diet, avoiding smoking, reducing stress, and moderate physical activity to increase the therapeutic effect of the protocol (51). An interesting phenomenon is the accumulation of increased amounts of vitamin C, mainly in its 
dehydrated form docosahexaenoic acid (DHA) in Kirsten rat sarcoma virus-mutant cancer cells (among others, colorectal cancer, lung cancer, pancreatic cancer, lymphoblastic leukaemia, chronic myelomonocytic leukaemia and Hodgkin's paragranuloma) and B-RAF-mutant cancer cells (melanoma) (52), compared to healthy cells. A high concentration of vitamin $\mathrm{C}$ in DHA form in cancer cells probably increases ROS production, disrupts the energy homeostasis of cells and leads to cell death (53). Very high doses of vitamin C, also in intravenous infusions, is not recommended due to a lack of adequate studies proving its efficiency, while replenishing a deficiency resulting e.g. from intense inflammation, is essential for normal collagen synthesis (54). A comparison of the concentrations of selected microelements in the blood of patients with lung cancer and healthy people in a study by Goodman et al. showed significantly lower levels of lutein, zeaxanthin, $\alpha$-carotene, $\beta$-carotene, retinol and $\alpha$-tocopherol in the patients (55). These elements exhibit antioxidant activity, participate in the proper functioning of the eyes, and reduce DNA damage (56). Supplementation of retinoids enhances the phagocytic ability of macrophages and release of transforming growth factor- $\beta$, which is involved in the induction of angiogenesis (48). The obtained concentrations were significantly lower in the group of smokers than in the non-smokers. The results of this study indicate the benefits of the inclusion of products rich in carotenoids in the daily diet due to their influence on the reduction of the risk of lung cancer (56). A higher intake of vegetable oils and a proper content of dietary fibre and vitamins are also beneficial, which was observed in both smokers and non-smokers (57).

Supplementation with selected particularly beneficial nutrients seems a promising solution to malnutrition in patients with lung cancer. Nevertheless, the potential toxic effect of an excessive amount of retinoids on the liver and skin, disturbing coagulation (vitamin E) and causing diarrhoea (vitamin $\mathrm{C}$ ), requires caution when consuming amounts that exceed the recommended daily allowance (51).

\section{Nutritional Bioactive Compounds}

Flavonoids also have beneficial antioxidant and antiinflammatory effects that inhibit arachidonic acid transformation cascades to pro-inflammatory prostaglandins, leukotrienes and thromboxanes (58). These same effects are observed for omega3 polyunsaturated fatty acids ( $\alpha$-linolenic acid, DHA, eicosapentaenoic acid) (59). It is also worth mentioning curcumin, whose anticancer effects against lung cancer cells have been described in pre-clinical in vitro and in vivo studies. The mechanism of action of this substance is associated with its influence on many molecular targets, among others, epidermal growth factor receptor, signal transducer and activator of transcription 3, phosphatidylinositol-4,5-bisphosphate 3kinase-AKT serine/threonine kinase $1 /$ mechanistic target of rapamycin kinase pathway and inhibitor of cyclo-oxygenase 2 (60). A synergistic effect between curcumin and some anticancer medications has also been reported (61). Unfortunately, there are no clinical data confirming the effectiveness of curcumin in lung cancer treatment. There are some reports from clinical data in literature that present a beneficial impact of curcumin on the spirometric parameters forced expiratory volume in $1 \mathrm{~s}$ (FEV1), FEV1/FEV1 as a percentage of vital capacity (62). It seems that a thorough knowledge of the mechanism of action, numerous pe-clinical studies and clinical experience in other therapeutic areas make this substance a promising candidate for clinical studies among patients with lung cancer.

\section{Protein and Amino Acids}

The appropriate process of activation and functioning of cytotoxic T-cells and memory cells requires a proper protein intake and the presence of nitric oxide, arginine and cysteine (13). These ingredients are also crucial in the process of tissue healing. Cysteine and methionine are associated with connective tissue and collagen synthesis $(54,63)$. Arginine, in turn, has a positive effect on the activity of the immune system, and its oxidation provides nitric oxide, which has an antiseptic effect and expands capillaries, favouring wound perfusion and thus increasing access to nutrients and oxygen (64). A higher intake of nucleotides, whose effectiveness was proven, among others, in a study conducted among surgical patients with brain, neck and oesophagus cancer, also enhances the functioning of the immune system (65). The precursor in the synthesis of nucleotides, nucleic acids, amino sugars and glutathione is glutamine. Glutamine is also essential to the endogenic synthesis of ornithine and arginine. Glutamine is an important element in the recovery process as it is a preferred source of energy for rapidly dividing cells, such as enterocytes and immune system cells (54). In a study by Kaya et al., supplementation of arginine, omega- 3 fat acids and nucleotides prior to surgery in patients with NSCLC and with no traces of malnutrition resulted in a lower level of albumins in the blood (by $14.69 \%$ ) compared to patients receiving non-supplemented diets (by 25.71\%). In addition, postoperative complications were less frequently observed in the patients from the study group (19.4\% vs. 44.4\%) (66).

\section{Conclusion}

Patients with Lung cancer show different nutritional status depending on the type of cancer and the stage of the disease at the time of diagnosis. The majority of patients - regardless of normal or excessive body weight - show changes in body composition at the time of diagnosis and before treatment which are not always associated with weight loss. With the course of therapy, the loss of muscle mass deepens and the 
side-effects of treatment, such as gastrointestinal disorders and loss of appetite as one of the consequences of chemotherapy and radiotherapy, or the process of wound healing after surgery, cause a progressive reduction of the body's resources and an increased likelihood of being unable to take food orally. The fact that the possibility of oral nutrition of patients with cancer declines results in the need to quickly include nutritional intervention in the form of a diet adapted to the current possibilities of food intake by the patient and increased nutritional demand. According to the European Society for Clinical Nutrition and Metabolism, during actively progressing disease, the demand for antioxidant and mineral components which take part in the correct immune response, increases by two- to three-fold in relation to the demand of healthy people. After an analysis of the literature, it seems justified to increase the supply of nutrients such as arginine; glutamine; vitamins $\mathrm{A}, \mathrm{B}, \mathrm{C}, \mathrm{D}$ and $\mathrm{E} ; \beta$-carotene, and microelements such as selenium and zinc, because it is these components that play an important role in the correct immune response and regeneration processes. However, it is worth mentioning that it is not recommended to routinely include typical multivitamin preparations, due to their possible interactions with anticancer drugs, and that the use of very high doses of vitamins and minerals may cause side-effects in addition to those already resulting from the anticancer therapy. Patient dietary supplementation should also be carried out during the regeneration period in order to replenish nutrient losses and rebuild body reserves, and its course should be agreed with experts in clinical nutrition.

\section{Conflicts of Interest}

PM is registered pharmacists with the Polish Pharmaceutical Chamber and is bound by the codes of practice and ethics. At the time of preparation of this article PM is employed as CEO of Piktorex sp. z o.o., an advisor to the Management Board of the Polish Pharmaceutical Group S.A, Adjunct Professor at the Cardinal Stefan Wyszyński University, Assistant Proffessor at the Department of Pharmaceutical Technology, Faculty of Pharmacy, Collegium Medicum in Bydgoszcz, Poland, President of Polish Pharmacy Trade Union (ZZPF) and General Secretary of Employed Pharmacist Europe (EPhEU), and as such, this Author must stress that the publication was written for academic interest only. At the time of preparation of this article, KB is also employed at the pharmaceutical company USP Zdrowie. The content outlined herein represents the individual opinions of the Authors and may not necessarily represent the viewpoints of their employers.

\section{Authors' Contributions}

$\mathrm{AK}, \mathrm{KB}$, TIC contributed to all aspects of the study's design. AK and $\mathrm{KB}$ wrote the article. UR, PM, KB and JP supervised the article and prepared the final version of the article. All listed Authors have contributed to the arguments of the article and have read and approved the final submission.

\section{References}

1 WHO: Fact Sheets-Cancer. Available at: https://www.who.int/ news-room/fact-sheets/detail/cancer [Last accessed on 19th August, 2020]

2 Smolle E and Pichler M: Non-smoking-associated lung cancer: a distinct entity in terms of tumor biology, patient characteristics and impact of hereditary cancer predisposition. Cancers 11: 204, 2018. PMID: 30744199. DOI: 10.3390/cancers 11020204

3 Gibson GJ, Loddenkemper R, Sibille Y and Lundback B: The European Lung White Book: Respiratory health and disease in Europe. Eur Respir J 42: 559-563, 2013. PMID: 24000245. DOI: $10.1183 / 09031936.00105513$

4 Didkowska J, Wojciechowska U, Mańczuk M, and Łobaszewski $\mathrm{J}$ : Lung cancer epidemiology: Contemporary and future challenges worldwide. Ann Transl Med 4: 50, 2016. PMID: 27195268. DOI: 10.21037/atm.2016.03.11

5 Yang P: Epidemiology of lung cancer prognosis: Quantity and quality of life. Methods Mol Biol 471: 469-486, 2009. PMID: 19109795. DOI: 10.1007/978-1-59745-416-2_24

6 Thun MJ, Hannan LM, Adams-Campbell LL, Boffetta P, Buring, JE, Feskanich, D, Falnders WD, Jee SH, Katanoda K, Kolonel LN, Lee I-M, Marugame T, Palmer JR, Robilo E, Sobue T, TangAvila E, Wilkens LR and Samet JM: Lung cancer occurrence in never-smokers: An analysis of 13 cohorts and 22 cancer registry studies. PLoS Med 5: e185, 2008. PMID: 18788891. DOI: 10.1371/journal.pmed.0050185

7 Duan P, Hu C, Quan C, Yi X, Zhou W, Yuan M, Yu T, Kourouma $\mathrm{A}$ and Yang K: Body mass index and risk of lung cancer: Systematic review and dose-response meta-analysis. Sci Rep 5: 16938, 2015. PMID: 26582414. DOI: 10.1038/srep16938

8 Sun Y, Li Z, Li J, Li Z and Han J: A healthy dietary pattern reduces lung cancer risk: A systematic review and meta-analysis. Nutrients 8: 134, 2016. PMID: 26959051. DOI: 10.3390/nu 8030134

9 Wang C, Yang T, Guo X and Li D: The associations of fruit and vegetable intake with lung cancer risk in participants with different smoking status: A meta-analysis of prospective cohort studies. Nutrients 11: 1791, 2019. PMID: 31382476. DOI: 10.3390/nu11081791

10 Krzakowski M, Jassem J, Antczak A, Chorostowska-Wynimko J, Dziadziuszko R, Głogowski M, Grodzki T, Kowalski D, Olszewski W, Orłowski T, and Rzyman W: Cancer of the lung, pleura and mediastinum. Oncol Clin Pract 15: 20-50, 2019. DOI: 10.5603/OCP.2018.0056

11 Allin KH, Boisen SE and Nordestgaard BG: Baseline C-reactive protein is associated with incident cancer and survival in patients with cancer. J Clin Oncol 27: 2217-2224, 2009. PMID: 19289618. DOI: $10.1200 / J C O .2008 .19 .8440$

12 Alifano M, Mansuet-Lupo A, Lococo F, Roche N, Bobbio A, Canny E, Schussler O, Dermine H, Régnard J-F, Burroni B, Goc J, Biton J, Ouakrim H, Cremer I, Dieu-Nosjean M-C, and Damotte D: Systemic inflammation, nutritional status and tumor immune microenvironment determine outcome of resected nonsmall cell lung cancer. PLoS One 9: e106914, 2014. PMID: 25238252. DOI: 10.1371/journal.pone.0106914 
13 Domagała-Kulawik J and Osińska I: Immune alterations in lung cancer -the new therapeutic approach. Pneumol Alergol Pol 82: 286-299, 2014. PMID: 24793154. DOI: 10.5603/PiAP.2014.0034

14 Navani N and Piro SG: Symptoms and signs of lung cancer. Chapter 5. In: Thoracic Malignancies. Spiro SG, Huber RM and Janes SM (eds.) Eur Respir Monogr 44: 71-87, 2009. DOI: 10.1183/1025448x.00044005

15 Iyer S, Taylor-Stokes G and Roughley A: Symptom burden and quality of life in advanced non-small cell lung cancer patients in France and Germany. Lung Cancer 81: 288-293, 2013. PMID: 23561304. DOI: $10.1016 /$ j.lungcan.2013.03.008

16 Polanski J, Jankowska-Polanska B, Rosinczuk J, Chabowski M and Szymanska-Chabowska A: Quality of life of patients with lung cancer. Onco Targets Ther 9: 1023-1028, 2016. PMID: 27013895. DOI: $10.2147 /$ OTT.S 100685

17 Wojciechowska U, Didkowska J and Zatoński W: Cancer in Poland - five-year survival rates by regions. Warsaw, The Maria Sklodowska-Curie Memorial Cancer Centre and Institute of Oncology, 2010. Available at: http://onkologia.org.pl/wpcontent/uploads/Przezycia_WOJ.pdf [Last accessed on November 23rd, 2020]

18 Nowicki A, Krzyminska $\mathrm{J}$ and Kowalewski J: Estimation of quality of life in patients after surgery for lung cancer. Contem Onco 10: 468-474, 2006. DOI: 10.1097/PPO.0b013e31820e15dc

19 Sloan JA: Metrics to assess quality of life after management of early-stage lung cancer. Cancer J 17: 63-67, 2011. PMID: 21263269. DOI: 10.1016/j.lungcan.2013.03.013

20 Poghosyan H, Sheldon LK, Levelle SG and Cooley ME: Healthrelated quality of life after surgical treatment in patients with non-small cell lung cancer: A systematic review. Lung Cancer 81: 11-26, 2013. PMID: 23562675. DOI: 10.1016/j.lungcan. 2013.03.013

21 Kao SC, Vardy J, Harvie R, Chatfield M, van Zandwijk N, Clarke $\mathrm{S}$ and Pavlakis N: Health-related quality of life and inflammatory markers in malignant pleural mesothelioma. Support Care Cancer 21: 697-705, 2013. PMID: 22936495. DOI: 10.1007/s00520-0121569-6

22 Yun YH, Kim YA, Sim JA, Shin AS, Chang YJ, Lee J, Kim MS, Shim YM and Zo JI: Prognostic value of quality of life score in disease-free survivors of surgically-treated lung cancer. BMC Cancer 16: 505, 2016. PMID: 27439430. DOI: 10.1186/s12885016-2504-x

23 Mock V, Atkinson A, Barsevick A, Cella D, Cimprich B, Cleeland C, Donnelly J, Eisenberger MA, Escalante C, Hinds P, Jacobsen PB, Kaldor P, Knight SJ, Peterman A, Piper BF, Rugo H, Sabbatini P and Stahl C: National Comprehensive Cancer Network. NCCN practice guidelines for cancer-related fatigue. Oncology 14: 151-161, 2000. PMID: 11195408.

24 Früh M, De Ruysscher D, Popat S, Crinò L, Peters S and Felip E: ESMO Guidelines Working Group. Small-cell lung cancer (SCLC): ESMO Clinical Practice Guidelines for diagnosis, treatment and follow-up. Ann Oncol 4(Suppl 6): vi99-105, 2013. PMID: 23813929. DOI: 10.1093/annonc/mdt178

25 Hoang T, Myung SK, Thi Pham T, Kim J and Ju W: Comparative efficacy of targeted therapies in patients with non-small cell lung cancer: A network meta-analysis of clinical trials. J Clin Med 9: 1063, 2020. PMID: 32283699. DOI: 10.3390/jcm9041063

26 Gróber U: Antioxidants and other micronutrients in complementary oncology. Breast Care 4: 13-20, 2009. PMID: 21373176. DOI: $10.1159 / 000194972$
27 Sanchez-Lara K, Turcott JG, Juarez E, Guevara P, Núñez-Valencia C, Oñate-Ocaña LF, Flores D and Arrieta O: Association of nutrition parameters including bioelectrical impedance and systemic inflammatory response with quality of life and prognosis in patients with advanced non-small-cell lung cancer: A prospective study. Nutr Cancer 64: 526-534, 2012. PMID: 22489794. DOI: 10.1080/01635581.2012.668744

28 Li R, Wu J, Ma M, Pei J, Song Y, Zhang X and Han B: Comparison of PG-SGA, SGA and body-composition measurement in detecting malnutrition among newly diagnosed lung cancer patients in stage IIIB/IV and benign conditions. Med Oncol 28: 689-696, 2011. PMID: 20422319. DOI: 10.1007/ s12032-010-9534-z

29 Gioulbasanis I, Baracos VE, Giannousi Z, Xyrafas A, Martin L, Georgoulias V and Mavroudis D: Baseline nutritional evaluation in metastatic lung cancer patients: Mini Nutritional Assessment versus weight loss history. Ann Oncol 22: 835-841, 2011. PMID: 20937647. DOI: $10.1093 / \mathrm{annonc} / \mathrm{mdq} 440$

30 Kłęk S, Jankowski M, Kruszewski WJ, Fijuth J, Kapała A, Kabata P, Wysocki P, Krzakowski M and Rutkowski P: Clinical nutrition in oncology: Polish recommendations. Oncol Clin Prakt 11: 172$188,2015$.

31 Xara S, Amaral TF and Parente B: Undernutrition and quality of life in non-small-cell lung cancer patients. Rev Port Pneumol 17: 153-158, 2011. PMID: 21664101. DOI: 10.1016/j.rppneu. 2011.01.006

32 Kovarik M, Hronek M and Zadak Z: Clinically relevant determinants of body composition, function and nutritional status as mortality predictors in lung cancer patients. Lung Cancer 84 : 1-6, 2014. PMID: 24560334. DOI: 10.1016/j.lungcan.2014.01.020

33 Kumar S, Dutt A, Hemraj S and Manipadybhima B: Phase angle measurement in healthy human subjects through bio-impedance analysis. Iran J Basic Med Sci 15: 1180-1184, 2012. PMID: 23653848.

34 Gupta D, Lammersfeld CA, Vashi PG, King J, Dahlk SL, Grutsch $\mathrm{JF}$ and Lis CG: Bioelectrical impedance phase angle in clinical practice: implications for prognosis in stage IIIB and IV non-small cell lung cancer. BMC Cancer 9: 37, 2009. PMID: 19175932. DOI: $10.1186 / 1471-2407-9-37$

35 Castanho IA, Lopes AJ, Koury JC, Tessarollo B, Silva AC and Nunes RA: Relationship between the phase angle and volume of tumours in patients with lung cancer. Ann Nutr Metab 62: 68-74, 2013. PMID: 23257390 . DOI: $10.1159 / 000345588$

36 Machado L, Saad IA, Honma HN, Morcillo AM and Zambon L: Evolution of performance status, body mass index, and six-minute walk distance in advanced lung cancer patients undergoing chemotherapy. J Bras Pneumol 36: 588-594, 2010. PMID: 21085824. DOI: $10.1590 / \mathrm{s} 1806-37132010000500010$

37 Nattenmüller J, Wochner R, Muley T, Steins M, Hummler S, Teucher B, Wiskemann J, Kauczor H-U, Wielpütz MO and Heussel CP: Prognostic impact of CT-quantified muscle and fat distribution before and after first-line-chemotherapy in lung cancer patients. PLoS One 12: e0169136, 2017. PMID: 28107410. DOI: 10.1371/journal.pone.0169136

38 Baracos VE, Reiman T, Mourtzakis M, Gioulbasanis I and Antoun S: Body composition in patients with non-small cell lung cancer: A contemporary view of cancer cachexia with the use of computed tomography image analysis. Am J Clin Nutr 91: 1133S-1137S, 2010. PMID: 20164322. DOI: 10.3945/ajen.2010. 28608C 
39 Ross PJ, Ashley S, Norton A, Priest K, Waters JS, Eisen T, Smith IE and O'Brien MER: Do patients with weight loss have a worse outcome when undergoing chemotherapy for lung cancers? Br J Cancer 90: 1905-1911, 2004. PMID: 15138470. DOI: 10.1038/ sj.bjc. 6601781

40 Rainer JK and Kämmerer U: Is there a role for carbohydrate restriction in the treatment and prevention of cancer? Nutr Metab 8: 75, 2011. PMID: 22029671. DOI: 10.1186/1743-7075-8-75

41 Prado CM, Lieffers JR, McCargar LJ, Reiman T, Sawyer MB, Martin L and Baracos VE: Prevalence and clinical implications of sarcopenic obesity in patients with solid tumours of the respiratory and gastrointestinal tracts: A population-based study. Lancet Oncol 9: 629-635, 2008. PMID: 18539529. DOI: 10.1016/S14702045(08)70153-0

42 Thomas PA, Berbis J, Falcoz PE, Le Pimpec-Barthes F, Bernard A, Jougon J, PorteH, Alifano M and Dahan M: EPITHOR Group. National perioperative outcomes of pulmonary lobectomy for cancer: The influence of nutritional status. Eur J Cardiothorac Surg 45: 652-619, 2014. DOI: 10.1093/ejcts/ezt452

43 Fiorelli A, Vicidomini G, Mazzella A, Messina G, Milione R, di Crescenzo VG and Santini M: EPITHOR Group. The influence of body mass index and weight loss on outcome of elderly patients undergoing lung cancer resection. Thorac Cardiovasc Surg 62: 578-587, 2014. PMID: 24959934. DOI: 10.1055/s0034-1373733

44 Jagoe RT, Goodship TH and Gibson GJ: The influence of nutritional status on complications after operations for lung cancer. Ann Thorac Surg 71: 936-943, 2001. PMID: 11269477. DOI: 10.1016/s0003-4975(00)02006-3

45 Dymarska E, Grochowalska A and Krauss H: The influence of nutrition on immune system. Immunomodulation by fatty acids, vitamin, minerals and antioxidants. Now Lek 82: 222-231, 2013.

46 Zagrodzki P: Selenium and the immune system. Postępy Hig Med Dośw 58: 140-149, 2004. PMID: 15077058.

47 Ibs KL and Rink L: Zinc - altered immune function. J Nutr 33: 1452-1456, 2003. PMID: 12730441

48 Krzysik M, Biernat $\mathrm{H}$ and Grajeta $\mathrm{H}$ : The influence of chosen nutrients on immune system functioning. Part II. Immunomodulatory effects of vitamins and trace elements on the human body. Adv Clin Exp Med 1: 123-133, 2007.

49 Ross V: Micronutrient recommendations form wound healing. Support Line 24: 3-9, 2002.

50 Pathak AK, Bhutani M, Guleria R, Bal S, Mohan A, Mohanti BK, Sharma A, Pathak R, Bardwaj NK, Prasad KN and Kochupillai V: Chemotherapy alone $v s$. chemotherapy plus high-dose multiple antioxidants in patients with advanced non-small cell lung cancer. J Am Coll Nutr 24: 16-21, 2005. PMID: 15670980. DOI: 10.1080/07315724.2005.10719438

51 Prasad KN: Antioxidants in cancer care: When and how to use them as an adjunct to standard and experimental therapies. Expert Rev Anticancer Ther 3: 903-915, 2003. PMID: 14686711. DOI: 10.1586/14737140.3.6.903

52 Oikonomou E, Koustas E, Goulielmaki M and Pintzas A: BRAF vs. RAS oncogenes: Are mutations of the same pathway equal? Differential signalling and therapeutic implications. Oncotarget 5: 11752-11777, 2014. PMID: 25361007. DOI: 10.18632/oncotarget. 2555

53 van de Reest J and Gottlieb E: Anticancer effects of vitamin C revisited. Cell Res 26: 269-270, 2016. PMID: 26768769. DOI: $10.1038 /$ cr.2016.7
54 Schlemmer M, Suchner U, Schäpers B, Duerr EM, Alteheld B, Zwingers T, Stehle P and Zimmer HG: Is glutamine eficiency the link between inflammation, malnutrition, and fatigue in cancer patients? Clin Nutr 34: 1258-1265, 2015. PMID: 25614125. DOI: 10.1016/j.clnu.2014.12.021

55 Goodman GE, Schaffer S, Omenn GS, Chen C and King I: The association between lung and prostate cancer risk, and serum micronutrients: Results and lessons learned from beta-carotene and retinol efficacy trial. Cancer Epidemiol Biomarkers Prev 12: 518-526, 2003. PMID: 12814997.

56 Arigony ALV, de Oliviera IM, Machado M, Bordin DL, Bergter L, Prá D and Henriques JA: The influence of micronutrients in cell culture: A reflection on viability and genomic stability. BioMed Res Int 2013: 597282, 2013. PMID: 23781504. DOI: $10.1155 / 2013 / 597282$

57 Gnagnarella P, Maisonneuve P, Bellomi M, Rampinelli C, Bertolotti R, Spaggiari L, Palli D and Veronesi G: Nutrient intake and nutrient patterns and risk of lung cancer among heavy smokers: Results from the COSMOS screening study with annual low-dose CT. Eur J Epidemiol 28: 503-511, 2013. PMID: 23576215. DOI: $10.1007 / \mathrm{s} 10654-013-9803-1$

58 Steinhilber D and Hofmann B: Recent advances in the search for novel 5-lipoxygenase inhibitors. Basic Clin Pharmacol Toxicol 114: 70-77, 2014. PMID: 23953428. DOI: 10.1111/bcpt.12114

59 Jańczyk W and Socha P: Clinical implication of $\omega-3$ polyunsaturated fatty acids supplementation. Standardy Medyczne Pediatria 6: 10-17, 2009

60 Wan Mohd Tajuddin W, Lajis NH, Abas F, Othman I and Naidu $\mathrm{R}$ : Mechanistic understanding of curcumin's therapeutic effects in lung cancer. Nutrients 11: 2989, 2019. PMID: 31817718. DOI: 10.3390/nu11122989

61 Ling Tan B and Norhaizan ME: Curcumin combination chemotherapy: The implication and efficacy in cancer. Molecules 24: 2527, 2019. PMID: 31295906 . DOI: 10.3390/molecules 24142527

62 Zhai T, Li S, Hu W, Li D and Leng S: Potential micronutrients and phytochemicals against the pathogenesis of chronic obstructive pulmonary disease and lung cancer. Nutrients 10: 813, 2018. PMID: 29941777. DOI: 10.3390/nu10070813

63 Posthauer ME: The role of nutrition in wound care. Adv Skin Wound Care 19: 43-52, 2006. PMID: 16477165. DOI: 10.1097/ 00129334-200601000-00015

64 Witte MB and Barbul A: Arginine physiology and its implication for wound healing. Wound Repair Regen 11: 497-511, 2003. PMID: 14617280. DOI: 10.1046/j.1524-475x.2003.11605.x

65 Talvas J, Garrait G, Goncalves-Mendes N, Rouanet J, VergnaudGauduchon J, Kwiatkowski F, Bachmann P, Bouteloup C, Bienvenu $\mathrm{J}$ and Vasson M-P: Immunonutrition stimulates immune functions and antioxidant defense capacities of leukocytes in radiochemotherapy-treated head \& neck and esophageal cancer patients: A double-blind randomized clinical trial. Clin Nutr 34: 810-817, 2015. PMID: 25575640. DOI: 10.1016/j.clnu.2014.12.002

66 Kaya SO, Akcam TI, Ceylan KC, Samancilar O, Ozturk O, and Usluer O: Is preoperative protein-rich nutrition effective on postoperative outcome in non-small cell lung cancer surgery? A prospective randomized study. J Cardiothorac Surg 11: 14, 2016. PMID: 26782276. DOI: 10.1186/s13019-016-0407-1

Received October 22, 2020

Revised November 20, 2020

Accepted November 24, 2020 